\title{
Ciudades (medias) y comunicación: cruces, nudos y aperturas
}

\section{ANA SILVA}

anasilva77@yahoo.com.ar - Universidad Nacional del Centro de la Provincia de Buenos Aires (UNICEN), Argentina / Consejo Nacional de Investigaciones Científicas y Técnicas (CONICET), Argentina.

\section{ARIEL GRAVANO}

arielgravano14@gmail.com - Universidad Nacional del Centro de la Provincia de Buenos Aires (UNICEN), Argentina / Consejo Nacional de Investigaciones Científicas y Técnicas (CONICET), Argentina.

Fecha de recepción: 14 de abril de 2017

Fecha de aceptación: 9 de mayo de 2017

\section{RESUMEN}

En este trabajo abordamos algunos antecedentes analíticos de la relación entre ciudad y comunicación y nos detenemos particularmente en ejes de análisis que tienen como base estudios de caso realizados con metodología etnográfica en distintas ciudades medias de la Provincia de Buenos Aires, Argentina. Partimos de un cruce entre dos sentidos restrictos de ciudad (físico-espacial) y comunicación (mass-mediática) que se anudan y permiten diversas aperturas, centrándonos en un rango urbano de escasa recurrencia en los análisis comunicacionales: ciudades medias.

Estas aperturas implican la necesaria ampliación del análisis tomando en cuenta las ideas de espacio urbano significacional y producción de lecturas divergentes. Finalmente re-anudamos ambos conceptos y los proyectamos hacia cuestiones ligadas a la agenda pública - desde las políticas de la ciudad y de la comunicación- y cuestiones de carácter teórico que nos permiten una conceptualización cruzada sobre lo urbano y lo comunicacional. En una primera parte veremos cómo ha sido abordada la relación entre ciudadycomunicación - ensuemergenciayactuali- dad-desdelainvestigación comunicológicaydesde un enfoque dialéctico-estructural sobre lo urbano. A continuación mostramosloscasosdereferencia, para finalmente alcanzar algunas conclusiones.

PALABRASCLAVE: ciudadesmedias, lo comunicacional, lo urbano, lo público, etnografía.

\section{ABSTRACT}

The aim of this work is to show the relationship between city and communication, beginning with the recognition of some antecedents and ending with lines of analysis based on ethnographic case studies located in different medium-sized cities of Buenos Aires Province, Argentina. We include a theoretical and analytical development concerning the joint between both components. We begin with the intersection between two restricted meanings of city (physical and spatial) and communication (massmedia) that become knotted and allow both apertures. And we refer to an urban range sparsely analyzed by communication studies: medium-sized cities. The apertures necessarily break with those restricted meanings, towards it expansion as significant urban space and production of divergent readings. Finally we re-knot both concepts and project them to public agenda - city and communication policies - and theoretical one, towards a conceptualization about the urban and the communicational, and their connections. In a first part we show how the relationship between city and communication has been addressed - in its emergence and in the present- by communication research and from a dialectic-structural approach about the urban. Then we show the cases of reference to finally reach some conclusions.

KEY WORDS: middle-sized cities, the communicational, the urban, the public, ethnography. 


\section{INTRODUCCIÓN}

En este trabajo abordaremos la relación entre ciudad y comunicación con una hoja de ruta que comienza por reconocer ciertos antecedentes y culmina con ejes de análisis que tienen como base nuestras investigaciones sostenidas, en estudios etnográficos, de distintas ciudades medias de la Provincia de Buenos Aires, Argentina ${ }^{1}$.

Dichos estudios de caso incluyen un desarrollo teórico-analítico que pretende articular elementos de ambas áreas de conocimiento. En uno de esos pioneros acercamientos a este tipo de problemas, y bajo el título "Ciudad y comunicación, densidades, ejes y niveles”, en 1997 Rossana Reguillo (2007 [1997]) señalaba que:

No bastará con elaborar inventarios — por más sofisticados que estos seanque den cuenta de la estructura de la oferta individual y comunicativa, de los equipamientos de la ciudad, de la cuantificación del desarrollo tecnológico y, en el mismo sentido, tampoco resulta pertinente un acercamiento que sólo focalice el "consumo" selectivo que, desde una posición específica, realizan los actores sociales. Ni determinismos ni voluntarismos permiten trabajar las relaciones - complejas - entre vida urbana y comunicación (2007, p. 1; el subrayado es nuestro).

Su propuesta se centraba en la necesidad de superar la mera relación entre la oferta de insumos tecnológicos comunicativos y urbanos y los consumos de los actores destinatarios de ambas provisiones ${ }^{2}$. Y destacaba la importancia de

plantear las diferencias entre ciudades capitales y ciudades de provincias, que conectan directamente con la discusión en torno a la relación -insuficientemente trabajada aún - entre la dimensión local y la dimensión nacional, condición para entender las profundas transformaciones que opera en el nivel de lo micro, la dimensión transnacional (ibíd., p. 2).

A partir de estos planteos, se abre un camino para pensar las relaciones y la configuración de un objeto complejo como las ciudades medias. Enfilando a éste, y parafraseando el título de Reguillo, nuestro trabajo se plantea, tal como se indica en el subtítulo, reflexionar sobre los cruces, los nudos y las aperturas, tratando de evitar reduccionismos y abrir horizontes de indagación Si los conceptos de ciudad y comunicación en sus acepciones restrictas, quedaron fijados en la idea físico-espacial de lo urbano, por un lado y al rasgo mass-

1 Desarrollamos nuestros trabajos dentro del Núcleo de Actividades Científicas y Tecnológicas denominado PROINCOMCSI (Producciones e Investigaciones Comunicacionales y Sociales de la Ciudad Intermedia), Facultad de Ciencias Sociales, Universidad del Centro de la Provincia de Buenos Aires.(www.soc.unicen.edu.ar/proincomsci). En lo referido al concepto de ciudades medias, aclaramos que no restringimos su definición a parámetros cuantitativos, como podrían ser el tamaño o el número de habitantes, sino a una dimensión significacional desde el registro de los imaginarios urbanos (Gravano, 2005; Boggi y Galván, 2016).

2 Reguillo parece apuntar en forma específica al determinismo tecnológico e, incluido en su categoría de voluntarismo, al enfoque light de los estudios culturales que se centran en la libertad interpretativa de los actores. 
mediático de la comunicación, por el otro, aquí nos proponemos avanzar en cuestiones que no reconocen mucha recurrencia en los análisis comunicacionales, ampliando su sentido y estableciendo un acercamiento problemático a eso que llamamos el espacio urbano significacional ${ }^{3}$ y la producción de lecturas divergentes ${ }^{4}$.

Finalmente re-anudamos ambos conceptos y los proyectamos hacia cuestiones tanto de agenda pública —-desde las políticas de la ciudad y de la comunicación-y cuestiones de carácter teórico que nos permiten una conceptualización cruzada sobre lo urbano y lo comunicacional. En una primera parte veremos cómo ha sido abordada la relación entre ciudad y comunicación —en su emergencia y actualidad - desde la investigación comunicológica y desde un enfoque dialéctico-estructural sobre lo urbano. Luego mostraremos algunos estudios de referencia surgidos de nuestras investigaciones, realizadas con metodología etnográfica, de distintas ciudades medias de la Provincia de Buenos Aires, Argentina.

\section{LA CIUDAD EN LA COMUNICACIÓN}

En el trabajo citado, Reguillo (2007) empieza usando una metáfora netamente urbana: "Quizá, como nunca, la comunicación sea una cuestión vital para salir del ghetto al que nos ha confinado la intolerancia, la negación del otro, el miedo y la indiferencia" (p. 1).

Ninguna de estas categorías (intolerancia, negación, miedo, indiferencia y el "otro") podría situarse en un estatuto de mero objetivismo, o de una ciudad física, solamente material. En consonancia con el énfasis de Reguillo en el carácter "coconstitutivo de la ciudad en las formas de socialidad específica" (ídem) de la vida urbana, apela a una visión propuesta por el numen dela Escuela Latinoamericana de Comunicación, Jesús Martín-Barbero. Esta ciudad es concebida y definida en su dimensión simbólica, ideológica yvivida. Responde a una tradición no muy reconocida por los estudios comunicacionales pero sí adoptada (y a veces - todavía - recién "descubierta" por algunos), que hemos llamado significacional, que se aparta del reduccionismo puramente espacial de lo urbano, específica del enfoque antropológico, pero que tiene como antecedentes a autores como el arquitecto Kevin Lynch (1965), el geógrafo David Harvey (1977), el antropólogo y arquitecto Amos Rapoport (1984), el semiólogo Armando Silva (1992), entre otros.

3 El concepto de lo urbano como espacio significacional se desarrolla en Gravano (2015) y se plasma en las investigaciones que citamos a lo largo de este artículo.

4 El reconocimiento de los "usos" creativos de los productos simbólicos, la producción negociada de sentidos y las lecturas "desviadas" o alternas cuenta con una amplia trayectoria en los estudios culturales, como parte del desplazamiento operado, en los '60 y'70, desde el análisis de los textos hacia el análisis de los "públicos” y su trabajo interpretativo. Entre muchos otros, deben mencionarse los estudios de Richard Hoggart (1957) y Stuart Hall (1973), a los que se sumarían los desarrollos de la denominada etnografía de audiencias, núcleo que tienen en The "Nationwide" audience de David Morley (1980) un mojón importante. Y en América Latina ha de mencionarse, una vez más, De los medios a las mediaciones de Jesús Martín-Barbero (1987). 
Es pensable que la comunicación "llegue" a la ciudad entendiéndola como socialidad, como forma de vida, en sus significados, códigos, imaginarios y como "múltiples identidades: barrios, grupos étnicos, corporaciones, 'tribus' diversas (...) y los movimientos sociales" (Reguillo, 2007, p. 4). Pero ¿cómo "llega" (o llegó) la ciudad a la comunicación?

El mismo trabajo de Reguillo nos da pistas. En primer lugar, la ciudad aparece como "escenario situacional" de "modos de vida específicos" (ibíd., p. 8), capaz de provocar interrogantes acerca de una dimensión simbólicocomunicacional inherente a lo social y sobre todo en la relación entre las representaciones y las prácticas colectivas. Esta postura trasciende el reduccionismo espacial-fisicista que cuestionaran los autores que recién citamos.

Como concepción amplia respecto a los reduccionismos, Reguillo se ampara en el descubrimiento delos actores en situación como clave metodológica, en las redes de intercambio simbólico y grupal, en las interacciones sociales ("choques, negociaciones, alianzas y enfrentamientos”, Reguillo, 2007, p. 5), pero parece quedar acotada a la constatación de la ciudad como escenario funcional de relaciones entre grupos y disputas, apelando a la teoría de los campos de Bourdieu, más que a una comprensión de lo urbano (como sistema de consumos colectivos) de la ciudad, en su carácter histórico-estructural (Gravano, 2015).

Una inevitable inmersión de la concepción del espacio en su dimensión significante, al decir de Raymond Williams (2001), nos ubica el ingreso de la ciudad en la agenda de las investigaciones en comunicación, que estuvo ligado al contexto de problematización del llamado "mediacentrismo" $y$ la consolidación de los estudios en comunicación y cultura ${ }^{6}$.

Entre fines de los' 80 y los'90, existieron diversas muestras de vitalidad en la reflexión sobre la ciudad desdela perspectiva dela comunicación. En el contexto latinoamericano, dan cuenta, de ello las investigaciones de Jesús MartínBarbero, Néstor García Canclini, Carlos Monsiváis, Renato Ortiz, Rossana Reguillo y Armando Silva, entre otros. Quizás una de las palabras clave que atraviesa estos abordajes sea, con resonancias benjaminianas, la de experiencia. Desde sus escritos seminales, Martín-Barbero llamaba a repensar las dinámicas de territorialización-desterritorialización ylas "transformaciones de la experiencia urbana", y a reconocer la centralidad de la ciudad "como si en la

5 De acuerdo con Martín-Barbero, el mediacentrismo "resulta de la identificación de la comunicación con los medios, ya sea desde el culturalismo mcluhiano, según el cual los medios hacen la historia, o desde su contrario, el ideologismo althusseriano, que hace de los medios un aparato de Estado. Desde uno u otro, comprender la comunicación es estudiar cómo funcionan las tecnologías o los 'aparatos', pues ellos hacen la comunicación, la determinan y le dan su forma" (2004, p. 219).

6 El campo de estudios en comunicación y cultura comienza a constituirse en las décadas del' 60 y'70, con divergencias teóricas e ideológicas que se manifestaron principalmente desde tres publicaciones específicas (Lenguajes, Comunicación y Cultura y Crisis) y la producción de los intelectuales vinculados a ellas - Oscar Steimberg, Oscar Traversa o Eliseo Verón, en el primer caso; Héctor Schmucler en el segundo y Aníbal Ford o Jorge Rivera en el tercero- - Pese a la confrontación explícita que sostuvieron estas diferentes vertientes, tenían en común la consideración del campo de la comunicación social como una cuestión de producción de sentido no reductible a los medios de comunicación masiva (Grimson \& Varela, 1999). 
ciudad se dieran cita en esta hora las mutaciones más de fondo, y fuera desde ahí desde donde nos fuera dado comprender el/los sentido/s de las transformaciones que atraviesan la sociedad y el hombre mismo" (Martín-Barbero, 2004, p. 273). En el prólogo a la edición de 1992 de Imaginarios urbanos de Armando Silva, Martín-Barbero destacaba la introducción de una mirada sobre la ciudad que nos descubre las diversas ciudades que la conforman: no sólo las que demarcan las topografías de los planificadores y urbanizadores sino aquellas otras que "produce/revela la topografía simbólica y sus territorios imaginarios. Se trata de una ciudad desconocida porque es la ciudad vivida" (Martín-Barbero; en Silva, 1992, p. 7).

Reguillo señalaba la importancia del cambio de enfoque, en tanto permitía problematizar ese papel de la ciudad "en formas de socialidad específicas" y no como un "telón de fondo" de las prácticas comunicativas. Y subrayaba la necesidad de realizar más investigación empírica a partir de abordajes situados que pudieran dar cuenta de las manifestaciones localizadas de procesos más generales, en particular respecto de los medios, las tecnologías digitales y las industrias culturales, los cuales con frecuencia son tomados desde un anclaje difuso en "lo nacional". Sobre ese mismo reclamo se inscribe nuestra propuesta de recuperar estudios de caso que permitan nutrir la discusión teórica y la generación de categorías de análisis etnográficamente informadas, hacia lo que avanzamos en la segunda parte de este artículo.

El tópico de la ciudad comenzó a ser recurrente en las reuniones académicas de investigadores en comunicación, sobre todo en los '90. Un hito al respecto es el grupo coordinado por Reguillo desde 1994 en las reuniones de la Asociación Latinoamericana de Investigadores en Comunicación (ALAIC) (Badenes, 2007).

En el mismo año se publica en castellano el libro de Alain Mons (1994), La metáfora social.Imagen, territorio, comunicación. Allí, establece quela relación entre comunicación y ciudad se da por articulación entre las imágenes de la ciudad y la circulación de mensajes mediáticos publicitarios en el contexto de la crisis económica, produciendo la necesidad de que lo que él llama la "ciudad metafórica" funcione como ariete de identidad y marca en el campo de la "batalla de las ciudades".

En 1995 aparece La ciudad informacional: tecnologías de la información, reestructuración económica yel proceso urbano-regional, de Manuel Castells. Pese a las acusaciones de proponer una perspectiva de determinismo tecnológico, tal vez el mérito de Castells - además de su temprana y crucial concepción de la ciudad como producción social del espacio (1974) - resida en haber reintroducidola discusión sobrelos mediosy las tecnologías desdela consideración de sus condiciones materiales de producción. En este libro se propone "analizar la relación entre las nuevas tecnologías de la información y los procesos urbanos y regionales en el contexto más amplio de la transformación histórica dentro 
de la cual estas tecnologías surgen y se desarrollan" (Castells, 1995, p. 22), y plantea la hipótesis de que este contexto se caracteriza simultáneamente por el surgimiento de un nuevo modelo de organización socio-técnica (al que llama modo de desarrollo informacional) así como por la reestructuración del capitalismo como matriz fundamental de la organización económica e institucional en nuestras sociedades.

En Argentina se publica en 1996 el libro de Alicia Entel, La ciudad bajo sospecha, que recupera resultados de una investigación desarrollada en la Universidad de Buenos Aires sobre la vivencia de distintos sectores sociales urbanos de los efectos de las políticas públicas privatizadoras y de los resultados de las privatizaciones del espacio público. Cinco años más tarde se da la recuperación de lecturas sobre la ciudad de algunos autores reconocidos como referentes teóricos por los estudios en comunicación, en particular aquellas de Walter Benjamin (2012) sobre París y Raymond Williams (2001) en El campo y la ciudad (algo menos, tal vez porque se trató de un texto tardíamente traducido al castellano ${ }^{7}$ ).

En el contexto latinoamericano, Martín-Barbero (2010) reivindica una genealogía propia donde aparecen, entre otros nombres, el del historiador José Luis Romero con su Latinoamérica, las ciudades y las ideas:

Romero trazó la ruta para un tipo de investigación cultural que, elaborando una tipología histórica de las ciudades [patricias, burguesas, masificadas, etc.] posibilita establecer relaciones de fondo entre la cultura, la política y la economía. (...) A la vez en sus procesos-macro y en las transformaciones de los mundos de vida (2010, p. 135).

También el uruguayo Ángel Rama, subraya Martín-Barbero,

nos hizo dos aportes básicos: una historia de la ciudad letrada y el despliegue de la idea de transculturación. Ciudad letrada nombra, en la sociedad colonial, no sólo el privilegiado lugar de los letrados sino un orden de los signos mediante el cual todos los ámbitos de la vida social reflejaban la colocación de todas las cosas en el lugar que les correspondía. (...) Ciudad dentro de la ciudad, no menos amurallada que la otra, y que subsistirá después de la independencia transformándose en una suerte de religión secundaria que ocupa el lugar de las religiones cuando estas comienzan su declinación en el siglo XIX (2010, p. 137).

7 La edición de Paidós salió en 2001, casi treinta años después de la publicación original en inglés del volumen (editado por Oxford University Press en 1973) En ese libro, Williams aborda, a partir de textos literarios las transformaciones históricas en la relación entre campo y ciudad en Inglaterra desde la revolución industrial, poniendo énfasis en la experiencia urbana y la conformación de modos de urbanidad, en tanto estilos de vida que expresan procesos de cambio en la organización socio-productiva. Se trata de un texto en el que el concepto williamsiano de estructura de sentimiento tiene una centralidad notoria, en torno del cual el galés retoma su insistencia acerca del componente material de la dimensión simbólica, la base material de la experiencia. Insiste, también, en la diversidad de ocurrencias concretas delos “asentamientos humanos", a las cuales el uso de categorías oposicionales como "campo" o "ciudad", o el énfasis en las metrópolis, tienden a opacar. 
Con estas miradas transversales, provenientes de la constitución de la relación entre ciudad y comunicación en torno al concepto de experiencia, y otros como ciudad vivida e imaginarios urbanos, quedan problematizadas asunciones clásicas, como la asociación entre urbanización y secularización, y otros procesos que terminan así abiertos en sus sentidos restringidos, atravesados con las preguntas desdela comunicación o, para ser más precisos, con la mirada que proponemos, lo comunicacional.

\section{LA COMUNICACIÓN EN LA CIUDAD}

Asíentendidala experiencia urbana, como dimensión sobrela que discurre la problematización del vínculo ciudad-comunicación, como un espacio vivido por los actores sociales, proponemos detenernos en una cuestión clave que atraviesa la relación entre comunicación y ciudad y es inherente a lo urbano: la cuestión de lo público.

En la década de los ochenta, marcada por la recuperación de la democracia formal en Argentina, las agendas institucionales y académicas supieron abrevar en los enfoques posibilistas de lo político, de base post-moderna en lo ideológico y reivindicadores de una ciudadanía anhelada y negada por las dictaduras, cuyos indicadores urbanos específicos encontraban en el espacio público su escenario más específico y sintomático.

Luego, bajo la amenaza y reinado del neoliberalismo, una orientación recurrente en la década del noventa fue la marcada preocupación por la privatización del espacio público y por la mediatización de la experiencia urbana, tópicos que se enfatizan hoy, dentro del proceso de restauración neoliberal, luego del interregno neo-desarrollista "con inclusión" y ampliación de derechos de la década kirchnerista.

Las distintas visiones sobre lo público o sobre el espacio público de la comunicación en las ciudades son el resultado de dos ejes de disyuntivas, que tensionan debates y posturas, a veces ocultas y otras explícitas: 1) una inclinación hacia el optimismo progresista y su opuesto escepticismo; cruzadas, a la vez, por 2) posturas idealistas-mecanicistas, por un lado, y dialécticas, por el otro. De la combinación de estos dos ejes podemos distinguir:

a. Una visión idealista-optimista, que es la que predomina en el sentido hegemónico de la noción de lo público moderno liberal, cuando se invocan valores como el bien común en abstracto, como si existiera por fuera de las relaciones sociales concretas y materiales, sobre todo de clase. La comunicación sería, en estos casos un instrumento de construcción o emergencia de esos valores ciudadanos yla ciudad su escenario más adecuado, también imbuida de lo que - por antonomasia - se considera que es la 
ciudad: el espacio público (de todos, libre, abierto, compartido participativamente).

b. Una visión idealista-pesimista, que es la que descree de la existencia de estos valores, o porque "se han perdido", avasallados por diversas fuerzas más poderosas pero no determinadas por procesos de poder real. La comunicación y la ciudad, para esta perspectiva, serían dos ámbitos de derrota de esos valores.

c. Una perspectiva dialéctica sobre lo público en la comunicación y la ciudad, que es aquella que, lejos de concebir los valores de manera ahistórica, apunta a la relación de totalidad que incluye la confrontación, dentro del sistema de poder, como una unidad de contrarios históricamente determinados. También puede oscilar entre un escepticismo crítico y un criticismo optimista, que constituyen matices dentro de esta postura.

Ex profeso no situamos a autores concretos en estas tendencias, porque muchas veces el mismo autor puede pendular y/o compartir visiones combinadas. Sobre lo público, como noción clave de nuestra forma de concebir la relación entre ciudad y comunicación, el aporte de Jürgen Habermas sobre "la opinión pública" moderna resulta fundamental, lo mismo que el de Hannah Arendt, que en parte hemos colocado - en otros trabajos - en ambas posiciones idealistas (Gravano, 2015 y 2016a). La base de este modelo de lo público de raíz kantiana, presupone a la ética individual como reserva de sentido contra el mundo del trabajo, la familia y el Estado.

Esta posición queda plasmada en el más reciente aporte de Armando Silva (2013): "la ética preserva a los individuos de los poderes institucionales y de presiones contra la rex-pública” (2013, p. 27); y, proyectando la idea ya clásica de Arendt y Habermas del sujeto sostenedor de esta ética en la "sociedad civil", especifica:

En quienes pueden tomar distancia de intereses particulares para apuntar a lo colectivo: intelectuales, científicos, investigadores, artistas, profesores universitarios, periodistas, funcionarios del Estado, empresarios modernos, gerentes con educación avanzada en sectores de punta, ONG y medios de comunicación (p. 25).

La alusión a lo comunicacional queda explícita dentro de esta idealizada lista de la élite liberal defensora de lo público. También puede incluirse dentro de este modelo, aunque con un matiz materialista, la cuestión recurrente de la "muerte de la ciudad", en rigor de la ciudadanía, de los derechos, del espacio público, a la que aluden otros autores (Castells, 1987; Delgado, 2002; Borja, 2013). 
Tomemos, como ejemplo, una cita que sintetiza una visión donde la comunicación es concebida en su sentido massmediático. Y la ciudad es considerada víctima de procesos epifenómicos y no estructurales, como su tamaño, su morfología, su funcionamiento, presentándola como causa del aislamiento comunicativo, desde una visión típica del idealizado ciudadano-habitanteconsumidor medio:

La ciudad actual, acaso como consecuencia de su gran tamaño, de la progresiva dependencia de sistemas expertos, de la edificación en altura, del enorme tránsito de vehículos, restringe los espacios para la interacción. Ello se agrava cuando reina la impunidad, los sistemas expertos funcionan mal y es difícil usar apaciblemente, y sin riesgo o conflicto, las plazas, las calles, las veredas. El habitante de la ciudad se refugia en su casa, desde donde se asoma a la ciudad por la ventana de la televisión. La ciudad massmediática contribuye al proceso de aislamiento. (Margulis, 2002, p. 532).

Una "ciudad actual" que parece encajar en el idealismo pesimista y remedar el ícono de la "jaula de acero", de Max Weber, cuando se preguntaba por el dilema de si era posible la vida auténticamente humana en la gran ciudad, cuestión estrechamente ligada — en la bisagra del siglo-a lo comunicacional.

En contrapartida con perspectivas apocalípticas sobresalen la ponderación de Martín-Barbero y su concepto de socialidad, del "sentirse juntos", en antagonismo con el "sálvese quien pueda", y en abierta proyección de lo que nosotros destacamos acá, (Martín-Barbero, 1994). También la profundidad analítica - en términos históricos y estructurales-de Richard Sennett sobre la descomposición de la vida pública en -o por- el capitalismo (Sennett, 2011) y específicamente sobre lo urbano (Sennett, 2010), de inspiración creativa marxista.

Dijimos más arriba que lo público es inherente al sistema urbano, que acotamos al conjunto de satisfactores de consumos colectivos que hacen al espacio material, institucional y socialmente construido al servicio de esa provisión, concebida como un derecho público y universal (Gravano, 2015). Podemos preguntar, entonces ¿qué es lo urbano de la ciudad?

Es lo que estructura a la ciudad, el sistema de servicios, de infraestructura, de equipamientos, que conforman el valor de uso de la ciudad, su sentido público. No estamos idealizando esa provisión o ese respeto al "derecho a la ciudad" como algo dado y abstracto, sino como una concepción por la cual se legitima la lucha por su cumplimiento efectivo, como parte de la instalación siempre contradictoria de lo público, componente crucial de lo urbano como sistema y que no se agota en el "espacio" público y tampoco se reduce al espacio demarcado de la ciudad.

Lo urbano de una ciudad, entonces, se detecta en la dialéctica del cumplimiento / incumplimiento de ese derecho, que incluye la contradicción 
entre el valor de uso necesario para la reproducción y el valor de cambio dado por la apropiación del excedente urbano dentro de la lucha de clases. En consecuencia, se podría responder cómo "llega" lo urbano (más que la ciudad) a la comunicación, o cómo se relaciona lo urbano con $l o$ comunicacional.

\section{CUATRO CLAVES DE LO URBANO MEDIO}

A partir de investigaciones realizadas durante más de veinte años en ciudades medias de la Provincia de Buenos Aires (sobre todo en Olavarría, Tandil, Azul y en menor medida en Mar del Plata y Bahía Blanca), hemos avanzado en cuatro hipótesis teóricas ${ }^{8}$ que aquí exponemos en torno a la articulación analítica entre lo comunicacional y lo urbano.

\section{Palimpsesto urbano}

La primera resulta del interrogante acerca de la relación entre la espacialidad yla temporalidad de los imaginarios del rango medio; dela construcción de una unicidad identitaria de la ciudad media - su supuesta homogeneidad-y su heterogeneidad real, marcada por las diversas formas de segregación socioespacial. La hipótesis afirma que

este imaginario se nutre de la dialéctica de las deshistorizaciones y rupturas de sentido, amparadas en la dimensión simbólica pero básicamente diacrónica, de una secuencia temporal de imágenes de la ciudad, a la manera de lo que definimos como un palimpsesto urbano (Gravano, 2016, p. 76).

En las ciudades del centro bonaerense reconstruimos la coexistencia de distintas imágenes identitarias superpuestas, procedentes de diferentes períodos históricos y con base en distintas fuentes de enunciación, compuestas a la manera del papiro antiguo que se borra parcialmente y se re-escribe sobre las texturas no desaparecidas del todo de trazos anteriores. Entre ellas, las imágenes comunes que identificamos son: la ciudad de frontera, que da cuenta de la construcción identitaria de estas localidades en su condición de "frontera con el indio" al sur del Río Salado en expansión durante el siglo XIX; la ciudad de tribalismos blancos, en la que se destaca la preponderancia étnicamente blanca, los modelos culturales europeizantes y sus espacios asociativos; y finalmente la conformación de imágenes emblemáticas en torno a los principales componentes del sistema productivo local: la industria cementera en Olavarría o el turismo en Tandil y Mar del Plata

8 Hemos definido como hipótesis teórica a aquella que guía un desarrollo de verificación más denso conceptualmente y con mayor recorrido estratégico que las hipótesis de trabajo, que ubicamos en una dimensión más tácticooperativa de la investigación (Gravano, 2016). 


\section{Homeostasis múltiple}

En segundo lugar, otra de nuestras hipótesis teóricas del imaginario medio es lo que denominamos homeostasis múltiple (Gravano, 2016), que consiste en la tendencia a suponer el equilibrio como condición previa y ulterior de todo proceso social. Es una extrapolación del principio biológico que establece la necesidad de un grado mínimo de equilibrio interno de todo organismo para subsistir. Da cuenta de las relaciones entre el sistema urbano de provisión de servicios públicos de consumo colectivo yla invocación al derecho universal de acceso a esos servicios públicos. Decimos que el eje ideológico preponderante es el homeostático, ya que se tiende a presuponer el equilibrio y no la contradicción dialéctica como lo "normal". Predomina un modo integrista y deshistorizador de concebir lo social, que está en la base de la racionalidad hegemónica.

"Esta homeostasis múltiple se encarna —en cada sistema-en reduccionismos de tipo tanto culturalista de concebir a actores y situaciones problemáticas cuanto subyacentemente biologicistas, aptos como dispositivos ideológicos para legitimar procesos de segregación y explotación" (2016, pp. 84 y 85). Su proyección a lo urbano tiene como efecto no sólo la muy recurrente concepción de la ciudad como un organismo sino un modo de "hacer ciudad" sobre la base de la naturalización de estados socio-culturales de normalidad y sus contrapartidas patológicas. Lo verificamos en los imaginarios de la discriminación y segregación urbanas: el prejuicio anti-villero, aún sin la existencia de las villas miseria metropolitanas, aplicado a conjuntos habitacionales estigmatizados, que llamamos "barrios mancha" (Gravano, 1995), como modelo ideológico subyacente a las políticas urbanas y transferido a los sistemas de consumos colectivos (de ahí la calificación de múltiple).

\section{Metropolismo}

En tercer lugar, a partir de la pregunta por la especificidad de la escala media se evidencia el predominio del modelo hegemónico que naturaliza una concepción abstracta de lo urbano como idéntico a lo metropolitano, lo cual se expresa tanto en la agenda teórica de los estudios urbanos cuanto en el sentido común y en la perspectiva preponderante de la gestión político-institucional de los municipios. De ahí la hipótesis que afirma que el modelo de dependencia del imaginario hegemónico metropolitano - el metropolismo-incide en la especificidad del funcionamiento de los sistemas institucionales y en el cumplimiento de sus propósitos particulares (Gravano, 2016). En las ciudades medias estudiadas lo urbano se relaciona con lo comunicacional de acuerdo con esta hipótesis. Para nuestro caso, en forma específica ese modelo se corporiza en la Capital Federal Buenos Aires y su Conurbano. Esta hegemonía inter-escalar consiste en naturalizar o suponer como sinónimos lo urbano y lo metropolitano o hasta lo mega-urbano, en desmedro de estas otras realidades de rango medio. 


\section{Tramas de poder}

Finalmente, como emergente más reciente de nuestros acercamientos, resulta la hipótesis de las tramas de poder, que sostiene que en estas ciudades se han ido estableciendo configuraciones de entramados vinculares de intereses y racionalidades entre sectores hegemónicos del empresariado, el sector público-político y franjas de profesionales que parecen funcionar como bloque histórico-institucional. El imaginario emblemático local es así aprovechado y co-construido de manera directa por estos intereses locales, y de forma mediatizada por la hegemonía metropolitano-globalizadora en la concepción de la vida urbana, de acuerdo con el modelo homeostático y amparado en las imágenes superpuestas del palimpsesto.

\section{LO URBANO Y LO COMUNICACIONAL EN CIUDADES MEDIAS}

Estas cuatro hipótesis, que hemos sintetizado en las palabras clave $p a-$ limpsesto urbano, homeostasis múltiple, metropolismo y tramas de poder, aparecen articuladas de manera específica en los casos considerados. A continuación recuperaremos algunos ejemplos donde pueden visualizarse esas articulaciones en las investigaciones propias basadas en estudios etnográficos de distintas ciudades medias de la Provincia de Buenos Aires.

\section{Vitrinas de papel}

Un caso en el que puede reconocerse la vinculación del palimpsesto urbano con las tramas de poder lo constituye la vigencia de los imaginarios de frontera en la producción actualizada de segregaciones socio-espaciales y la configuración de relaciones de poder sostenidas sobre el imaginario pueblerino del reconocimiento ("acá nos conocemos todos"). Esto pudimos observarlo al indagar la producción, reproducción y circulación de imaginarios identitarios urbanos en los medios de comunicación locales, como parte de la articulación de sentidos de lo medio de la ciudad.

Uno de los primeros trabajos al respecto consistió en una etnografía del circuito de producción y consumo de un suplemento para jóvenes del único diario local de Olavarría ${ }^{9}$ (Silva, 2011). El suplemento contenía mensajes enviados por los lectores, letras de canciones y, mayoritariamente, fotografías tomadas en diferentes lugares de la ciudad que eran punto de encuentro para los jóvenes. El fotógrafo del diario recorría esos lugares y era requerido por los distintos grupos para que les tomara fotos a ser publicadas en el suplemento. La concurrencia a esos espacios, en ciertos horarios, suponía la aceptación de mostrarse y fotografiarse y que luego esas imágenes se publicaran en el medio para continuar el circuito de exhibición. De la misma manera, esos espacios

9 Se trataba del suplemento para adolescentes y jóvenes "El Pasillo", del diario El Popular. 
eran evitados por quienes no querían ser vistos, fotografiados o identificados con los grupos que allíse reunían. A partir de ese interjuego de territorialidades juveniles - que extendían los parques y plazas al "territorio de papel” del periódico- recuperamos la metáfora de las vitrinas urbanas acuñada por Armando Silva (1992), en tanto nos permitía dar cuenta de la espacialidad escópica que se configuraba en el espacio urbano, a partir de las presencias - y ausenciasen lugares para ver y ser vistos que se cargaban simbólica y valorativamente. Planteamos entonces la hipótesis de que el suplemento se constituía en una verdadera "vitrina urbana mediática", extendiendo sobre el papel las significaciones e imaginarios de las territorialidades juveniles olavarrienses.

En una etapa ulterior focalizamos en la producción de narrativas urbanas mediáticas a partir de la publicación de fotografías familiares "sociales" en la prensa de circulación local de las ciudades de Olavarría y Tandil. A partir de este trabajo indagamos en los entramados singulares entre lo privado y lo público de la ciudad intermedia, los modos en que ésta es habitada y enunciada por las múltiples historias que la componen, al tiempo en que las narrativas particulares son "habitadas" por la ciudad como imaginario, como dimensión co-constitutiva (en los términos de Reguillo, 2007) de lo social y no mero continente o "telón de fondo".

Las tramas de poder aparecían naturalizadas en las exhibiciones de pertenencia a diferentes grupos (clubes, escuelas, familias, grupos amicales) y, una vez más, en el "reconocimiento"; reafirmación de la condición media de la ciudad en la que "nos conocemos todos" y, al mismo tiempo, de la consolidación de un capital relacional por parte de ciertos "apellidos" y "profesionales" reconocidos. Como reverso de la vitrina el trabajo de campo permitió acceder a las sutiles prácticas de exclusión presentes en esos espacios, la segregación de quienes no se sentían convocados por esas prácticas ("eso no es para mí") por no ser, precisamente conocidos y reconocidos. En la circulación de la vitrina mediática se actualizaban imaginarios de frontera con sus consiguientes efectos de exclusión - simbólicos, pero bien concretos en tanto enlazan con las posibilidades o no de acceso a puestos de trabajo, a recomendaciones o afiliaciones institucionales (como en el caso de un club de golf de la ciudad de Tandil, al que para asociarse se requiere la invitación de al menos dos miembros).

Las imágenes fotográficas se constituían asimismo en un elemento significativo para la construcción de la memoria social de las transformaciones de la ciudad y de los estilos de vida de sus habitantes, y con ellos, de la actualización selectiva de las capas del palimpsesto local. El proceso de reconversión de los imaginarios urbanos que habíamos constatado en otros trabajos (Boggi, 2016) se evidenciaba también en las narrativas mediáticas construidas a partir de las fotografías que daban cuenta de los procesos de transformación de estas ciudades intermedias. 
El trabajo de archivo sobre un amplio corpus de ejemplares de periódicos locales nos permitió advertir cómo hasta fines de la década de 1960 las fotografías que daban cuenta de transformaciones edilicias y urbanísticas de las ciudades estaban claramente insertas en una narrativa de progreso y utilizadas como ilustración del crecimiento, la industrialización y la modernización de estos centros urbanos. Esta narrativa comienza a resquebrajarse como discursividad dominante a partir de la década de 1970, en un contexto de retracción de la economía Argentina y de inevitable crisis, seguida de una reconversión de las imágenes de pujanza y pleno empleo que habían dominado los imaginarios con los que olavarrienses y tandilenses se identificaban ante propios y extraños hasta ese momento. En la década de 1990 — cuando los elevados índices de desempleo y el generalizado "estado de malestar" producto de las políticas neoliberales dejaban poco espacio para optimismos-, identificamos como sintomática la aparición de una serie de suplementos en los diarios locales dedicados a la publicación de fotografías antiguas de la ciudad, con un claro tono nostálgico y una narrativa orientada al pasado, a esa "época de oro" añorada de una ciudad deshistorizada (Silva \& Boggi, 2016).

\section{La magia digital urbana}

Hemos estudiado los procesos de "modernización” institucional asociados a la incorporación de tecnologías de la información yla comunicación(TIC) en el ámbito del Estado Municipal, concretamente a partir de la implementación del Programa Nacional de Gobierno Electrónico en la localidad de Tandil. El trabajo de campo evidenció las distintas racionalidades puestas en juego en esas interacciones, atravesadas por los imaginarios identitarios urbanos de la ciudad media de un modo que consideramos crucial, ya que atañe a uno de los núcleos en torno de los cuales se teje dicha identidad: la de las relaciones cara a cara y los vínculos de solidaridad — así como las "picas"10 — entre conocidos, una de cuyas expresiones más notorias es la "gauchada"11 (Silva, 2012). En este caso adquirían centralidad las formas en que la implementación de un modelo de gestión "globalizado" se superponía a la fragmentación socio-espacial ya existente en el medio local y a la propia dinámica de las interacciones sociales que se establecían en las áreas afectadas al programa. De esta manera, las TIC, concebidas desde los propósitos manifiestos como "puentes" entre la administración municipal y la ciudadanía, eran vividas en algunos casos como verdaderas "barreras". Losimaginarios metropolistas y homeostáticos se expresaban en la identificación directa de la presencia de las TIC con la "modernización”, el “adelanto", la mayor eficiencia en los procesos de gestión, a los que se oponía el "atraso" concebido como rasgo propio de los vínculos pueblerinos.

\footnotetext{
10 Rivalidades.

11 Gesto desinteresado de solidaridad.
} 
El análisis de la incorporación de las TIC en la gestión pública planteaba nuevas aristas para abordar los entrecruces entre los imaginarios sociales urbanos, la planificación de base metropolitana-global y la cotidianeidad de las prácticas también mediatizadas por los imaginarios de los actores que gestionan en y desde lo local. En esa dialéctica se inscriben las tensiones entre las visiones de "mejora" de la gestión y los modos de producción y/o reproducción de las desigualdades-fronteras, que no son sólo digitales, en la distribución territorial del sistema de sistemas de servicios urbanos.

La vinculación de los imaginarios hegemónicos de la ciudad pujante y la ciudad de la naturaleza, junto a la segregación urbana como proyección de la actualizada ciudad de frontera del palimpsesto, condicionan los procesos de planificación de la gestión que suponen como sinónimos tecnificación y modernización, por los que la tecnología queda encaramada con un cierto sentido mágico.

La planificación, además, que se realiza desde el modelo homeostático, que parte de la idealización del no-conflicto y la presunción del equilibrio como normalidad, dejando el conflicto en el lugar de lo inesperado, frente al que se actúa después y no como una instancia de la planificación misma.

Los modos de gestionar el sistema urbano, sobre los que se supone que vienen a intervenir las TIC, se encuentran así entramados con las identidades históricamente configuradas de la ciudad media en sus imágenes superpuestas y sus redes de sociabilidad. Estas últimas son definidas por los actores como basadas principalmente en interacciones cara a cara, en relaciones de reconocimiento, reciprocidad, pertenencia, compromisos o dones y, también, en enemistades, segregaciones, exclusiones y "picardías"; en suma, en las tramas locales de poder.

Y en esto, el metropolismo, concretamente la imagen de la ciudad de Buenos Aires, opera también como modelo de diferenciación, de "lo que no hay que hacer", cuando la proyección de modelos a seguir se traslada a otras referencias de lo metropolitano-central, frente a lo cual los modos de sociabilidad pueblerino-periféricos aparecen significados en términos de "defensa" de la identidad local y también de "atraso" respecto del adelanto tecnológico, concebido como clave tan mágica como homeostática.

\section{Las ciudades metro-telematizadas}

Uno de los ejemplos salientes del metropolismo relacionado con lo comunicacional es lo que Cristina Leiro (2015) analizó a fines de los 90 y comienzos de los 2000 como la "ciudad telemática" o "meta-imagen mediática como referente". En su trabajo registró un imaginario hegemónico de Olavarría asociado a la propia imagen de "ciudad" con la de la metrópolis (Buenos Aires) vista por televisión, en contraste con la "chacra asfaltada" (aludiendo a un espacio rural pavimentado) de la propia ciudad de rango medio. 
Así, es posible seguir constatando en los espacios públicos de estasciudades bares, restaurantes, salas de espera, lobbies de hoteles, comercios televisores ostentando noticieros donde se muestran baches, choques, robos, secuestros y demás signos de urbanidad de la ciudad de Buenos Aires.

\begin{abstract}
La protagonista principal en los medios masivos electrónicos es la metrópoli, ella se ha convertido en el centro de todas las miradas, y en escenario privilegiado de todos los hechos noticiables. Detrás del 'cristal de una sola cara' se oculta el resto del país, como si solamente los hechos sucedieran en Buenos Aires, produciendo una resignificación de los espacios a través del intercambio de imágenes con referencia en "el" gran escenario donde se suceden las prácticas rituales legitimadas: la Capital (Leiro, 2015, p. 76).
\end{abstract}

Leiro vincula lo mediático con lo urbano propio de la ciudad media, que desde este modelo no se considera propiamente "una ciudad":

\begin{abstract}
Si bien la revolución tecno-científica tiene como principales protagonistas a los medios de comunicación, es también una revolución territorial - reorganización de los espacios socio-históricos cotidianos en el contexto urbano, con deslocalización y descentralización-. Surge así una nueva cultura urbana centralizada, cuyo principio es lo efímero - la novedad-y lo reiterativo - los estereotipos-. Una cultura urbana metropolitana que (...) se produce e irradia desde la metrópoli, Buenos Aires, como un gran estudio televisivo donde la comunicación mediatiza, crea un espacio imaginario-virtual que reorganiza los espacios sociales y resignifica los imaginarios urbanos. Esos imaginarios en donde aparecen las meta-imágenes virtuales, las imágenes de Olavarría dentro del marco de la imagen televisiva de Buenos Aires (ibíd., p. 77).
\end{abstract}

Sin embargo, a la par o más bien dentro del imaginario metropolista se da la paradoja de una especie de contraparte que pondera a la ciudad media como polo opuesto al metropolitano, por la tranquilidad y armonía de la vida pueblerina, que implicaría un grado mayor de comunicación inter-personal, de grupos primarios, donde "los vecinos se conocen todos", "te cruzás por la calle y saludás, porque todos somos vecinos".

Esta preponderancia comunicacional del metropolismo es estudiada por María Eugenia Iturralde en su análisis de la implementación de políticas de comunicación en Azul, Olavarría y Tandil(2016). La centralización mediática en Buenos Aires se evidencia no sólo en la agenda porteñocéntrica a la que hacía referencia Leiro, sino también en la concentración de la propiedad y la radiación centrípeta de los mapas de medios, en notoria contradicción con los principios de federalismo comunicacional. La investigación de Iturralde muestra cómo los entramados de intereses locales mediatizan la implementación de las políticas de comunicación e inciden en la opción por la no regulación en el nivel municipal. 


\section{Historias (a) medias}

Recientemente, este tipo de asunciones imaginarias se reforzaron con los efectos locales y metropolitanos del masivo recital del Indio Solari en Olavarría (marzo de 2017), que mostró un contraste pleno de paradojas entre ambas imágenes, ya que la masividad del ágora "ricotera" de convocatoria "nacional" (aunque no publicitada mass-mediáticamente desdela metrópolis) forzó cierta tendencia local a una defensa claustrofílica (Gubern, 1987), a partir de la reivindicación de esa "tranquilidad invadida".

Tres años antes, con la recuperación en Olavarría del nieto 114 por Abuelas de Plaza de Mayo, la ciudad había producido también elementos de análisis respecto al metropolismo. En principio, porque Ignacio había sido criado por una familia de trabajadores rurales de un poblado cercano a la ciudad de Olavarría, era un músico conocido localmente y su abuela había resultado ser precisamente Estela de Carlotto, la líder del organismo defensor de derechos humanos. De ahí la trascendencia extra-local.

Para las primeras planas de medios masivos nacionales, esto es: metropolitanos y hegemónicos, la noticia adquirió impacto de agenda notoria. Y para los olavarrienses, que mayormente consumen comunicacionalmente esos mismos medios, les había llegado, una vez más, la Historia, con mayúsculas, ese preconcepto de algo que acontece siempre lejos, es céntrico y, en el fondo, no es «nuestro», sino de otros (lugares y personajes) más importantes (Gravano, 2016b, p. 306).

La Historia con mayúsculas, para ese imaginario local, siempre es metropolitana. Y en este caso, hablamos de "llegada" a la ciudad porque la cuestión de los desaparecidos siempre fue de dimensión histórica nacional, en tanto los desaparecidos de Olavarría nunca habían dejado de ser — para el imaginario hegemónico- locales y, en rigor, menos que locales: de unos pocos en la ciudad. El nieto recuperado tuvo, en cambio, impacto nacional. $Y$ verificamos un verdadero

festival de necedades movileras reproducido desde los medios televisivos metropolitanos [que] se nutrió de expresiones como «esta es la casa de Guido [su nombre como persona apropiada], como vemos, en medio del caaaampo", «los vecinos dicen que sus padres adoptivos es gente tranquila y trabajadora, porque es gente de estelugar, comolo que seve, donde sieempre parece pasarlo mismo, todo parece tranquilo», «el nieto de Carlotto se crió en esto, en el campo, alejado de la gran ciudad». «Una familia de nivel primario crió en el campo a este nieto de Carlotto», completó otro de los medios nacionales (ibíd., p. 307).

Es el contraste de escala el que produce la naturalización de los valores de la dicotomía: "acá nunca pasa nada": nada de lo malo que acontece en la "gran" ciudad (Buenos Aires), porque Olavarría “todavía” se asocia con una dimen- 
sión verdaderamente humana, auténtica, pura, incontaminada, mundo en el que se habría criado el nieto descubierto por "toda la ciudad", de acuerdo con el modelo de la identidad local no metropolitana, incluso asumido por el propio protagonista: "Sí, estuve en Buenos Aires, y hasta me saludaban los porteños, pero porque me reconocían; acá [en la ciudad media] te saludás porque te ves nomás" (ibíd., p. 317).

Estas concepciones de la ciudad media vivida o de lo pueblerino con un grado mayor de comunicación primaria, cálida, cara a cara, cuerpo a cuerpo, escomún en los imaginarios de centros urbanos más pequeños y en ellas parece flotar la oposición deshistorizada del modelo dicotómico rural / urbano. Pero, en rigor, siempre son el resultado del contraste con la imagen de la gran urbe metropolitana de relaciones secundarias, mediatizadas y "frías". Y aún se constata dentro del imaginario metropolitano, en relación al centro y a los barrios, o en términos de ciudadanía o vecinalismo (Gravano, 2011).

En el caso del juicio y del nieto, entonces, lo pueblerino se articula con la tramalocal de complicidades empresariales y políticas con el terrorismo militar de Estado y un tejido narrativo de "toda" la ciudad en torno a una historia $a$ medias que ocultaba la existencia del campo de detención y la identidad originaria de aquel niño.

\section{Territorios manchados}

La hipótesis que hemos definido como homeostasis múltiple se verificó en la administración de una de las ciudades estudiadas, cuando se intentaron desarrollar unidades territoriales que paliarían la insatisfacción de la provisión de servicios públicos mediante la descentralización de éstos en los barrios "menos favorecidos", "de modo que los vecinos no tengan que ir al Municipio [en el centro de la ciudad] a realizar trámites o a reclamar" como invocaban los funcionarios. No está demás aclarar que este tipo de barrios estigmatizados en muchos sentidos coincide con esas partes de la ciudad manchada:

El barrio es periférico para el municipio, pero después tenés gente común laburante, lo que pasa es que a la vez está lleno de vagos. Además, hay un problema más grande, que es la falta de educación (almacenero) ${ }^{\mathbf{1 2}}$.

Este barrio es medio bravo, la van a pasar mal. No vengan de noche porque van a pasar un mal momento [...] el barrio está peligroso, hay mucha delincuencia. Hay familias que se pelean entre ellos, andan a los tiros todo el tiempo, a los tiros y se matan entre ellos ${ }^{\mathbf{1 3}}$.

Una de las consignas de la intervención en el servicio territorial fue "trabajar sobre la autoestima” de estos sectores y apelar a lo comunicacional:

12 Registro de Pereyra, Bourgeois, Lerchundi y Castro.

13 Ibídem. 


\begin{abstract}
Nos proponemos con este programa que] el sujeto (niño, joven, adulto) pueda pensar que no tiene por qué hacer lo que viven en su familia, si son bebedores o violentos (...), que puede ser otra cosa, que puede pensar en salir del barrio. Después se trabaja en el programa o lo que sele proponga y finalmente, mostrar lo que se hace, que se vea. Esto es como que cierra el círculo, que salga en el diario y mostrar otra cosa de lo que se supone (en la ciudad), hace que se fortalezca también su autoestima (Coordinadora STM).
\end{abstract}

Rosana Sosa y Analía Umpiérrez (2016) se preguntan qué están diciendo desde la órbita municipal cuando apelan a fortalecer la autoestima' como clave de la intervención. Y responden que se constituye un marco donde "los dispositivos de gobierno de la población en la 'sociedad del control' (Deleuze, 1991) demandan que las personas actúen sobre sí para conseguir sus objetivos y si no se logra son los propios actores, sus capacidades (o su falta) lo que explica el fracaso.

Se confunden, entonces, las consignas educativo-formativas con las estrictamente dependientes del mercadolaboral y con lo territorial de esos barrios, ya que como tarea del servicio descentralizado se explicita terminar exitosamente la escolaridad, "salir del barrio" y ser reconocidos por "los medios", con lo que nuevamente queda focalizada la atención en un centro hegemónico que lograría así restaurar homeostáticamente la ciudad normal, donde la publicidad parecería garantizar esa normalidad.

Parecería que el barrio entonces no podría trabajar hacia adentro en pos de una mejora colectiva, de conquistar el acceso a consumos urbanos y condiciones de habitabilidad, entre otros. Y como remate, la necesidad de "salir en el diario", mostrar a la ciudad lo bueno que se hace a través de los medios de comunicación. Estas referencias estarían dando cuenta de cómo la gestión social se va conformando como un modelo administrativo que desliza la idea de "identidad" a "imagen”, ¿todo es cuestión de imagen? ¿Los medios son las "vitrinas urbanas" que permiten conformar nuevas identidades? (Sosa \& Umpierrez, 2016, p. 205).

\title{
Fronteras educativas
}

La proyección de la homeostasis urbana al sistema educativo se evidencia en las investigaciones de Umpierrez (2016) sobre el creciente número de profesores de educación física advenidos a la dirección de escuelas en la Provincia de Buenos Aires:

Priorizar en la selección de directores a aquellos que cuenten con un perfil particular: que compartan (supuestamente) imaginarios higienistas y disciplinadores respecto del papel de la educación destinada a determinados sectores de la población a través del control del cuerpo y la acción, daría cuenta delíneas estratégicas en la conducción de la población. Esto aportaría a promover la inclusión de los y las jóvenes a partir de formatos sostenidos mayoritariamente 
por la contención y el control más que por prácticas centradas en los saberes y la construcción de una ciudadanía participativa y dialógica (2016, p. 234).

Segregación y sometimiento de grupos específicos de la población, en un escenario en el que instituciones y actores se constituirían en "gendarmes" custodios de "nuevas fronteras" (ibíd.).

\section{Siberización de la salud}

Una segregación que se verifica también en el sistema de salud en Olavarría, emblematizada como "capital regional de la salud", que establece fronteras espaciales y de respecto a la atención del consumo colectivo. El sistema de atención a la salud mental sobrellevó un proceso de siberización (definido así por los agentes específicos), al ser secundarizado organizacionalmente y trasladado a la periferia urbana, precarizando además las condiciones laborales. La investigación de Bárbara Galarza al respecto concluye que:

El análisis de la política pública de salud mental municipal junto al de la organización del espacio de atención demuestra que el sistema de salud mental se estructura con una lógica de gestión que tiende a la dispersión de la población, tanto de pacientes como de profesionales (2015, p. 79).

Lo que muestra Galarza sirve para ver cómo esa dispersión también se explica en términos estructurales por la tendencia a la privatización de la atención junto a una paradójica explicitación comunicacional mediática del auto-cuidado, que encubre procesos de abandono a la individualidad y autoresponsabilización(delasfamilias delos pacientes), semejantea la homeostasis señalada recién respecto a la política territorial.

Las políticas públicas, en el caso específico de la salud mental, son herederas del higienismo social. El análisis de estas instituciones y sus políticas públicas señala un complejo proceso de reconversiones ideológicas que operan en la esfera de la comunicabilidad y de la organización socio-espacial y que tienen por resultado la expansión de lo psiquiátrico más allá de las fronteras urbanas (Ibíd., p. 80).

No es casual, resalta la investigadora, que el mismo discurso oficial que ostentaba cómo:

la salud debería convertirse en escenario del desarrollo y de la generación de riqueza, (...) en la época misma en que observábamos el aumento dela cuestión psiquiátrica en el sistema público municipal en las afueras de la ciudad, en una de sus calles más céntricas se comenzaba a construir una clínica psiquiátrica privada" (ibídem).

Dehecho, paralelamente al anuncio del intendente en los medios locales de 
grandes cambios en la gestión del sistema público de salud mental, los dueños de la clínica a la que el Hospital periférico derivaba sus pacientes con prestación privada evaluaron rentable construir una filial en el centro de la ciudad, ya que el espacio comunica que la salud mental en realidad, más que un derecho, es para quien pueda pagarla.

\section{Emblemas marcados}

Junto a estos procesos de invocada descentralización pero real dispersión y segregación, no es casual que se detecten centralizaciones hegemónicas en imaginarios que reivindican, emblematizaciones propias de las ciudades medias. Por ejemplo, la línea de analizar la emergencia de la "ciudad marca" para el desarrollo local competitivo (Mons, 1992) en el imaginario promovido desde las tramas hegemónicas queda verificada en las investigaciones donde se muestra la complicidad empresarial-militar en el terrorismo de Estado detrás del emblema de la "capital del trabajo" y "del cemento" (Lemiez, 2016), en tiempos de acumulación, y en la re-emblematización de la ciudad "diversificada" y "emprendedora" (Sosa, 2016), ya lejos de esos climas socio-económicos de "bienestar". Los intentos comunicacionales de instituir "marcas" locales o regionales (Gravano, 2006) a partir de esos emblemas y re-emblemas necesariamente se contrastan con los fracasos reales de esas ciudades "soñadas" por una planificación homeostática, donde el futuro se erige como una repetitiva añoranza (Gravano, 2016b).

\section{HACIA APERTURAS CONCLUSIVAS}

Dijimos que partiríamos del cruce entre los reduccionismos de las concepciones de ciudad y comunicación, que las restringen a su dimensión físicoespacial y mass-mediática, respectivamente. Luego ahondaríamos en su anudamiento y una apertura, a partir de los antecedentes mencionados, hacia la comprensión de la ciudad como espacio significacional y de la comunicación como proceso social de producción de sentidos en conflicto. En estos pases entre comunicación y ciudad de ida y vuelta vimos la ciudad en la comunicación con eje en la experiencia o ciudad viva y cómo "llega" lo urbano (más que la ciudad) a la comunicación o, en síntesis, cómo se relaciona lo urbano con lo comunicacional.

Sobre la base de las investigaciones realizadas en ciudades medias bonaerenses, propusimos el re-anudamiento de ambos términos y su proyección hacia cuestiones de agenda pública: las políticas de la ciudad y las políticas de comunicación, tal como se ve especialmente en los casos abordados de implementación de la gestión con TIC, la aplicación de políticas de comunicación a nivel municipal, los programas de descentralización territorial y las políticas de salud mental. Y de agenda teórica: desplazamiento desde la 
ciudad y la comunicación a lo urbano —en su carácter histórico-estructuraly lo comunicacional - como proceso simbólico material que incluye y no se reduce a los medios-.

Vinculamos analíticamente los casos con cuatro hipótesis elaboradas inductivamente a partir de nuestras investigaciones. El palimpsesto, la homeostasis múltiple, el metropolismo y las tramas de poder anudados en las prácticas de exclusión y reproducción de hegemonía del "reconocimiento pueblerino", la estigmatización de los "barrios mancha", la fronterización educativa, la segregación de la salud mental, la concepción homeostática de la gestión digital y la preponderancia de lo metropolitano como modelo ideológico plasmado en la pantalla mediática y en los modos de gestión de lo público, que nos permiten proyectar una profundización dela relación entre locomunicacionaly lourbano en las ciudades medias. 


\section{REFERENCIAS}

Arendt, H. (2007). La condición humana. México: Paidós.

Badenes, D. (2007). Comunicación y ciudad: líneas de investigación y encuentros con la Historia Cultural Urbana. En Questión, 14(1). (Disponible en: http://perio.unlp. edu.ar/ojs/index.php/question/article/view/354)

Benjamin, W. (2012). El París de Baudelaire. Buenos Aires: Eterna Cadencia.

Boggi, S. (2016). Identidades de pirotecnia: reconversiones imaginarias de ciudades bonaerenses. En Boggi, S, Gravano, A. y Silva, A. (editores), Ciudades vividas: sistemas e imaginários de ciudades medias bonaerenses (pp.93-112). Buenos Aires: Café de las Ciudades.

Boggi, S. y Galván, N. (2016). Ciudad media, ciudad intermédia: ¿ni chicha nilimonada? En Gravano, A., Silva, A. y Boggi, S. (editores), Ciudades vividas: sistemas e imaginários de ciudades medias bonaerenses (pp. 25-48). Buenos Aires: Café de las Ciudades.

Borja, J. (2013). Revolución urbana y derechos ciudadanos. Buenos Aires: Café de las Ciudades.

Castells, M. (1974). La cuestión urbana. Madrid: Siglo XXI.

Castells, M. (1987). Movimientos sociales urbanos. México: Siglo XXI.

Castells, M. (1995). La ciudad informacional. Tecnologías de la información, reestructuración económica y el proceso urbano. Madrid: Alianza.

Deleuze, G. (1991). Posdata sobre las sociedades de control. En Ferrer, C. (compilador), El lenguaje literario (pp. 15.23). Montevideo: Nordan.

Delgado Ruiz, M. (2002). Etnografía del espacio público. En: Revista de Antropología Experimental, $\mathrm{N}^{\circ} 2$ (Disponible en: http://revistaselectronicas.ujaen.es/index. $\mathrm{php} / \mathrm{rae} / \mathrm{article} / \mathrm{view} / 2111 / 1853)$.

Entel, A. (1996). La ciudadbajo sospecha: comunicación y protesta urbana. Buenos Aires: Paidós.

Galarza, B. (2015, junio). Segregación y dispersión en la atención del derecho a la salud mental en el centro de la provincia de Buenos Aires. En Intersecciones en Antropología, No 16, pp. 69-83 (Disponible en: http://www.scielo.org.ar/scielo. php?script=sci_arttext\&pid=S1850-373X2015000100004).

Gravano, A. (1995). Imaginario urbano, barrios mancha y calidad de vida en la ciudad intermedia. Hacia un modelo de análisis. En Intersecciones, $\mathrm{N}^{\circ} 2$, Facultad de Ciencias Sociales, Universidad del Centro de la Provincia de Buenos Aires, pp. 51-61. 
Gravano, A. (1999). Palimpsesto urbano: sobre-escritura de huellas diacrónicas de la ciudad imaginada. En Etnía, $\mathrm{N}^{\circ}$ 42-43, Museo Damaso Arce, Olavarría, Argentina, pp. 47-67.

Gravano, A. (compilador) (2005). Imaginarios sociales de la ciudad media: emblemas, fragmentaciones y otredades urbanas, estudios de Antropología Urbana. TandilOlavarría, Argentina: UNICEN-REUN.

Gravano, A. (2011). ¿Vecinos o ciudadanos? El fenómeno NIMBY: participación social desde la facilitación organizacional. En Revista de Antropologia, Vol. 54, pp. 191230. (Disponible en: http://www.revistas.usp.br/ra/article/view/38590).

Gravano, A. (2006, enero-diciembre). Imaginarios regionales y circularidad en la planificación: el caso del TOAR. En Intersecciones, $\mathrm{N}^{\circ} 7$, pp. 305-323. (Disponible en: http://www.scielo.org.ar/scielo.php?script=sci_arttext\&pid=S1850 373X2006000100022).

Gravano, A. (2015). Antropología de lo urbano. Buenos Aires: Café de las Ciudades.

Gravano, A. (2015a). Des-historias del centro bonaerense. En Lanteri, S. y Pedrotta, V. (editores), La frontera sur de Buenos Aires en la larga duración (pp. 245-276). La Plata, Argentina: Archivo Histórico de la Provincia de Buenos Aires.

Gravano, A. (2016). Tres hipótesis sobre la relación entre sistema urbano e imaginarios. En Boggi, S, Gravano, A. y Silva, A. (editores), Ciudades vividas: sistemas e imaginários de ciudades medias bonaerenses (pp. 69-90). Buenos Aires: Café de las Ciudades.

Gravano, A. (2016a). Épicas barriales: lo público-político vivo. En Cuadernos de Antropología, Vol. 26, pp. 1-25. (Disponible en: http://revistas.ucr.ac.cr/index. php/antropologia/article/view/27304).

Gravano, A. (2016b, enero-junio). Historia a medias e historias medias: imaginarios de lo pueblerino en el contexto de juicios al terrorismo de Estado. En Tabula Rasa, N $^{\circ} 24$, pp. 303-324. (Disponible en: http://www.redalyc.org/ pdf/396/39646776013.pdf).

Grimson, A. y Varela, M. (1999). Recepción, culturas populares y medios. Desplazamientos del campo de comunicación y cultura en la Argentina. En Grimson, A. y Varela, M. Audiencias, cultura y poder. Estudios sobre televisión (pp. 43-98). Buenos Aires: Eudeba.

Gubern, R. (1987). El simio informatizado. Madrid: Fundesco.

Habermas, J. (1994). Historia y crítica de la opinión pública. México: Gustavo Gili.

Hall, S. (1975). Encoding and decoding in the television discourse. In Education and Culture, $\mathrm{N}^{\circ}$ 6. Strasbourg: Council of Europe.

Harvey, D. (1977). Urbanismo y desigualdad social. Madrid: Siglo XXI. 
Hoggart, R. (1957). The uses of Literacy. Aspects of Working-Class Life with special references to publications and entertainments. Harmondsworth, UK: Penguin.

Iturralde, M. E. (2016). Democratización de la comunicación en ciudades medias. En: En Newsletter, Jornadas Proincomsci 2016. Facultad de Ciencias Sociales, Universidad del Centro de la Provincia de Buenos Aires. Olavarría, Argentina: UNICEN.

Leiro, C. (2005). Esto no es una ciudá, la meta-imagen mediática como referente. En Gravano, A. (compilador), Imaginarios sociales de la ciudad media: emblemas, fragmentaciones y otredades urbanas, estudios de Antropología Urbana (pp. 69-78). Tandil-Olavarría, Argentina: UNICEN-REUN.

Lemiez, G. (2016). No todo lo que brilla es cemento: relaciones laborales y conflicto en la industria cementera de Olavarría. En Boggi, S, Gravano, A.y Silva, A. (editores), Ciudadesvividas: sistemas e imaginários de ciudades medias bonaerenses (pp. 275300). Buenos Aires: Café de las Ciudades.

Lynch, K. (1966). La imagen de la ciudad. Buenos Aires: Infinito.

Margulis, M. (2002, septiembre-diciembre). La ciudad y sus signos. En Estudios sociológicos, 3(20), pp. 515-536. (Disponible en: http://www.redalyc.org/ pdf/598/59806001.pdf).

Martín-Barbero, J. (1987). De los medios a las mediaciones. México: Gustavo Gilli.

Martín-Barbero, J. (1994, octubre). Mediaciones urbanas y nuevos escenarios de comunicación. En Revista Sociedad, N 5, Facultad de Ciencias Sociales, Universidad de Buenos Aires (UBA), pp. 35-47.

Martín-Barbero, J. (2012, marzo-abril). El poder de las masas urbanas. En Revista NuevaSociedad $\mathrm{N}^{\circ} 238$,pp.41-53. (Disponible en:http://nuso.org/media/articles/ downloads/3831_1.pdf).

Martín-Barbero, J. (2004) Oficio de cartógrafo. Travesías latinoamericanas de la comunicación en la cultura. Buenos Aires: FCE.

Martín-Barbero, J. (2010). Notas para hacer memoria de la investigación cultural en Latinoamérica. En Nelly Richard (ed.) En torno a los Estudios Culturales. Localidades, trayectorias y disputas. Buenos Aires: CLACSO.

Mons, A. (1994). La metáfora social, imagen, territorio, comunicación. Buenos Aires: Nueva Visión.

Morley, D. (1980). The Nation wide audience: structure and decoding. London: British Film Institute.

Rama, Á. (1985). La ciudad letrada. En: Morse, R. y Hardoy, E., Cultura urbana latinoamericana (pp. 11-37). Buenos Aires: Clacso. 
Rapoport, A. (1984). La cultura y el orden urbano. En Agnew -et al.-, The city in cultural context. Boston: Allen

Reguillo, R. (2007). Ciudad y comunicación: densidades, ejes y niveles. En Diálogos de la comunicación, $\mathrm{N}^{\circ} 74$. (Disponible en: http://dialogosfelafacs.net/wp-content/ uploads/2015/74/74-revista-dialogos-ciudad-y-comunicacion.pdf).

Sennett, R. (2010). Carne y piedra, el cuerpo y la ciudad en la civilización occidental. Madrid: Alianza Editorial.

Sennett, R. (2011). El declive del hombre público. Barcelona: Península.

Silva, Ana. (2011). Imágenes e imaginarios urbanos en la "ciudad de las sierras". En Iluminuras, $\mathrm{N}^{\circ} 11$, pp. 1-22, Banco de Imagens e Efeitos Visuais, UFRGS, Porto Alegre, Brasil.

Silva, Ana. (2012, julio-diciembre). De 'puentes' y 'barreras'. Interfaces digitales en la gestión pública. En La Trama dela Comunicación, Vol.17,pp.239-253. (Disponible en: http://www.latrama.fcpolit.unr.edu.ar/index.php/trama/article/view/428).

Silva, Ana. y Boggi, S. (2016). Estudios sobre imaginarios de ciudades medias. En Boggi, S, Gravano, A. y Silva, A. (editores), Ciudades vividas: sistemas e imaginários de ciudades medias bonaerenses (pp. 49-68). Buenos Aires: Café de las Ciudades.

Silva, Ana y Gravano, A. (2016). Gobierno electrónico e imaginarios urbanos: “iqué te van a atender por internet en esta ciudad!”. En Boggi, S, Gravano, A. y Silva, A. (editores), Ciudadesvividas:sistemase imaginários deciudadesmediasbonaerenses (pp. 175-192). Buenos Aires: Café de las Ciudades.

Silva, Armando.(1992).Imaginarios urbanos, Bogotáy Sao Paulo: culturay comunicación urbana en América Latina. Bogotá: Tercer Mundo Editores.

Silva, Armando. (2013). Imaginarios, el asombro social. Bogotá: Universidad Externado de Colombia.

Sosa, R. (2016). La educación que necesita la ciudad reconvertida. En Boggi, S, Gravano, A. y Silva, A. (editores), Ciudades vividas: sistemas e imaginários de ciudades medias bonaerenses (pp. 237-250). Buenos Aires: Café de las Ciudades.

Sosa, R. y Umpierrez, A. (2016). Gestión social de territorios y escuelas de inclusión obligada: un protagonismo ríspido. En Boggi, S, Gravano, A. y Silva, A. (editores), Ciudades vividas: sistemas e imaginários de ciudades medias bonaerenses (pp. 193218). Buenos Aires: Café de las Ciudades.

Umpierrez, A. (2016). Nuevas fronteras: ¿directores gendarmes? En Boggi, S, Gravano, A. y Silva, A. (editores), Ciudades vividas: sistemas e imaginários de ciudades medias bonaerenses (pp. 219-236). Buenos Aires: Café de las Ciudades.

Williams, R. (2001). El campo y la ciudad. Buenos Aires: Paidós. 


\section{IDENTIFICACIÓN DE LOS AUTORES}

Ana Silva es Doctora por la Facultad de Filosofía y Letras de la Universidad de Buenos Aires (UBA), mención en Antropología Social. Es Licenciada en Comunicación Social por la Facultad de Ciencias Sociales, Universidad Nacional del Centro de la Provincia de Buenos Aires (UNICEN), Argentina. Realizó una estadía postdoctoral en el Banco de Imágenes y Efectos Visuales del Programa de Posgrado en Antropología Social (IFCH- UFRGS) de Porto Alegre, Brasil. Investigadora Asistente del Consejo Nacional de Investigaciones Científicas y Técnicas (CONICET), Argentina. Integrante del Núcleo de Producciones e Investigaciones en Comunicación Social de la Ciudad Intermedia (PROINCOMSCI), Facultad de Ciencias Sociales de la UNICEN, y del Centro de Estudios de Teatro y Consumos Culturales (TECC) de la Facultad de Arte de la UNICEN. Entre 2011 y 2013 fue directora del Departamento de Historiay Fundamentación Teórica (Facultad de Arte, UNICEN). Docente dela carrera de Realización Integral en Artes Audiovisuales de la UNICEN. Ha publicado distintos artículos en revistas especializadas y las compilaciones Ensayos sobre arte, comunicación y politicas culturales junto a Fuentes y Santagada (2012) y Políticas, comunicación y organizaciones en la primera década del milenio junto a Bustingorry e Iturralde (2011). Sus temas de investigación atraviesan las áreas de la comunicación social y la antropología urbana.

Ariel Gravano es Doctor en Ciencias Antropológicas por la Universidad de Buenos Aires (UBA), e investigador del Consejo Nacional de Investigaciones Científicas y Técnicas (CONICET), Argentina. Es profesor titular de Antropología Urbana en la Universidad Nacional del Centro de la Provincia de Buenos Aires (UNICEN). Integra consejos científicos de distintas publicaciones académicas latinoamericanas y es miembro de posgrados en Antropología y Arquitectura. Dirige el Núcleo de Actividades Científicas y Tecnológicas "Producciones e Investigaciones Comunicacionales y Sociales de la Ciudad Intermedia” (PROINCOMSCI) de la UNICEN. Ha publicado Antropología de lo barrial (2003), El barrio en la teoría social (2005) y Antropología de lo urbano (2015) y, como compilador, Miradas urbanas-visiones barriales (1995), Imaginarios sociales de la ciudad media (2005) y Ciudades vividas: sistemas e imaginarios de ciudades medias bonaerenses (2016). Sus áreas de actividad son la antropología de lo urbano, la cultura popular y la antropología organizacional.

\section{REGISTRO BIBLIOGRÁFICO}

Gravano, Ariel y Silva, Ana (2017). Ciudades (medias) y comunicación: cruces, nudos y aperturas. InMediaciones de la Comunicación, 12(1), 39-65. 